\title{
The Use of CLT in the Arab Context: A Critical Perspective
}

\author{
Basma Alwazir \\ English Language Institute, King Abdul Aziz University \\ Jeddah, Saudi Arabia \\ E-mail: balwazir@kau.edu.sa \\ Nadia Shukri \\ English Language Institute, King Abdul Aziz University \\ P.O. Box 42890, Jeddah, KSA, 21551 \\ E-mail: ndshukri@gmail.com
}

Received: December 2, 2016 Accepted: December 19, 2016 Published: December 21, 2016

doi:10.5296/ijele.v5i1.10486 URL: http://dx.doi.org/10.5296/ijele.v5i1.10486

\begin{abstract}
One of the main aims behind learning English as a foreign language (EFL) is to communicate effectively with other speakers of the English language. The justification for concentrating on the teaching and learning of English as a second language (L2), and as a foreign language, is that it is the lingua franca (Klimczak-Pawlak, 2014) and the primary language used for communication around the world (Rich, 2014). English language learners are given limited chances to practice speaking in authentic situations in class, and teaching to communicate effectively in an authentic environment is often overlooked. Communicative Language Teaching (CLT) emphasizes meaning and communication in language learning, and with CLT the goal is to improve learners" "communicative competence" (Richards \& Rodgers, 2001). Nevertheless, challenges are faced when applying CLT in the EFL classrooms. Consequently, the purpose of this paper is to critically explore elements of the CLT approach and to better understand some of the cultural difficulties involved in its application. The paper will propose more application of the CLT in EFL classrooms, in place of language teaching techniques currently used in the Arab context. This paper will also examine issues dealing with the theoretical background of CLT, and focus on the implementation of activities that can encourage students' communicative competence.
\end{abstract}

Keywords: CLT, language teaching, EFL, cultural background, Arab context 


\section{Introduction}

Communicative language teaching (CLT) is considered as an approach to language teaching (Larsen-Freeman, 2000; Richards and Rodgers, 2001). It is established on the notion that the key purpose of language is communication, and its foremost objective thus is for learners to improve their communicative competence (Hymes, 1972; Richards and Rodgers, 2001). In other words, the aim of CLT is to make use of real-life situations that require communication.

The goal of teaching English as a foreign Language (EFL) is to develop learners' communicative competence. For EFL learners to become proficient speakers, they not only need to master the grammatical rules of the language, but more importantly they need to know how to use the target language effectively in different situations through ample exposure to authentic learning materials.

The purpose of this paper is to investigate the importance of the CLT approach inside the EFL classroom and to highlight some difficulties involved in its application. The paper intends to address the significant role of CLT in EFL classrooms, as well as shed light on English language learning in Saudi Arabia and the Middle East, with reference to the challenges in the EFL classrooms. Lastly, the paper will suggest implementation of language learning strategies (LLS) for the referred to EFL classrooms.

\section{CLT Background}

CLT was applied in the English curriculum in many countries during the 1980s, after it started in European countries in the 1970s (Littlewood, 2007; Ozsevik, 2010 Doctoral dissertation). Furthermore, Ying states that CLT became the main language teaching methodology in the world, after it appeared in English speaking countries (2010, unpublished master dissertation). There was a need for language instructors to pay significant attention to communicative proficiency, rather than mastery of structure, as was realized by European linguists (Savignon, 1991; Littlewod, 2007). 'Communicative competence' is also referred to as "competence that enables us to convey and interpret messages and to negotiate meanings interpersonally within specific contexts", as first presented by Hymes in 1966 (Brown, 2007, p. 246).

The commonly recognized meaning of communicative competence, as presented by Canale and Swan (1980), states that there are four different components of communicative competence which are grammatical competence, discourse competence, sociolinguistic competence and strategic competence. Since CLT primarily aims at developing language learners' communicative competence (Tsai, 2007, unpublished doctoral dissertation), Pei-long (2011) confers that language teaching should focus on communicative ability rather than the mastery of sentence structure.

Ultimately, Communicative Language Teaching facilitates learning by equipping the learners with all the skills needed for them to be able to incorporate their knowledge of the language to the point where it sustains them from communicating in a more functional manner. Thus, the significance of Communicative Language Teaching (CLT) concept consequently refers to the "integration of grammatical and functional teaching." 


\subsection{The CLT Approach}

Communicative Language Teaching (CLT) is not viewed as a teaching method with a defined record of classroom practices; rather, it is regarded as an approach to second language teaching. Richards \& Rogers (2001) state that the need is "to focus in language teaching on communicative proficiency rather than on mere mastery of structures" (p.153). Therefore, teachers must set situations in the lesson where students are most likely to encounter and relate to in their real lives and cultural context. More importantly, the real-life class simulations may change day to day, so as the students' motivation to learn comes from their desire to communicate in expressive ways about meaningful real life topics and situations.

While learners apply the CLT approach, they are presented with opportunities to apply genuine settings necessitating communication competence (Hymes, 1972). The CLT approach is communicative by default; therefore, it is more effective in class activities where learners are able to communicate and interact with their peers in pair or group work. Richards \& Rogers (2001) proclaim that CLT means more than the "integration of grammatical and functional teaching" (p. 155). Clearly unlike the audio-lingual method which depends on repetition and redundancy, learner responses and reactions are more genuine in nature with CLT. Interestingly, as the genuine simulations change from day to day, so will learner responses and reactions. According to Richards \& Rogers (2001), the CLT approach is effective because it targets the development of the four skills that acknowledge the intertwined dependence of language and communication, and thus it aims to have students become communicatively competent (p. 155).

On a similar note, British linguist D. A. Wilkins (1972) presented an analysis of communicative meaning, with a functional definition of language where language learners need to understand and express. Thus, making CLT different from other approaches and methods. According to Littlewood (1981: 1), "One of the most characteristic features of CLT is that it pays systematic attention to functional as well as structural aspects of language".

\subsection{CLT Characteristics}

There are two versions of CLT, as stated by Richards \& Rogers (2001). The first is the weak version that stresses the importance of providing learners with opportunities to use their English for communicative purposes. The second, on the other hand, is the strong version that advances the claim that language is acquired through communication (p. 155). Accordingly, it is not a question of activating an existing knowledge of language, but rather of encouraging the development of the language system. Subsequently, Howatt (1984) summarizes the weak and strong versions as learning to use English versus using English to learn it (p. 279).

Brown (1994) presents four interconnected characteristics that can be used as a definition of communicative language teaching. To begin with, he suggests that language-teaching goals should contain all the components in communicative competence. Hence, after the learners study the target language, they should be able to read printed materials of average difficulty and write relatively properly in the target language. As such, and according to Brown (1994), learners will be able to do more than just listen to a large part of the authentic speech 
utterances, speak relatively fluently in the target language and make themselves understood.

Learners should be engaged in the practical and functional use of language for meaningful purposes. Although organizational competence is not the dominant focus; nevertheless, it should be considered as a facilitator to accomplish the purpose. Hence, the central focus of CLT is on real communication, and with real communication, organizational competence cannot be excluded from the functional use of language.

With CLT, fluency should take on more importance than accuracy in order to keep learners meaningfully engaged and motivated in their language use. With CLT, there is more focus specifically on speaking the target language with fluency and being understood by the listener, while teaching grammar and structure of the sentence are not as important as fluency according to Brown (1994). Similarly, it is significant that teachers do not point out student errors directly when they speak, as student's immediate utterances are a part of the development of their communication skills. As such, it is suggested instead to note student errors during a given activity and then point errors out to them after the activity.

It may be important for the EFL learner to be encouraged to communicate and interact with the instructor as well as with peers in pair or group work, both in and out of class activities. The above stated elements of communication are part of the foundation of the CLT approach, which corresponds with my experience as an English Language Institute (Eli) classroom instructor. As suggested by Richards \& Rogers (2001), the above CLT elements highlight the 'integration of grammatical and functional teaching' (p.155). Moreover, Littlewood (1981) conveys "one of the most characteristic features of communicative language teaching is that it pays systematic attention to functional as well as structural aspects of language" (p.1).

Some of Finocchiaro and Brumfit's (1983) selected explanations of CLT listed below further emphasize the features of CLT highlighting student's experience as L2 learners: 1) Meaning is paramount; 2) Dialogues, if used, center around communicative functions and are not normally memorized; 3) Contextualization is a basic premise; 4) Language learning is learning to communicate; 5) Effective communication is sought; 6) Drilling may occur, but peripherally; 7) Comprehensible pronunciation is sough; 8) Any device that helps the learners is accepted - varying according to their age, interest, etc. 9)Teachers help learners in any way that motivates them to work with the language;...10) Language is created by the individual, often through trial and error; 11) Fluency an acceptable language is the primary goal; Accuracy is judged not in the abstract but in context; 12) Students are expected to interact with other people, either in the flesh, through pair and group work and intrinsic motivation will spring from an interest in what is being communicated by the language (p. 90-93).

The above selected features list highlights some distinctive features of CLT. More importantly, the features bring to light interpretations that practitioners can identify with CLT, specifically from the learners' needs and perspectives.

\section{Challenges of CLT in the EFL Classrooms}

Centering on communicative proficiency in teaching the language, instead of simply focusing on the mastery of structure, is an essential facet of teaching a language and one of the 
challenges of CLT in the EFL classroom (Richards and Rodgers, 2001). Correspondingly, Hymes (1972) claimed that "knowing a language does not warrant grammar mastery because in some social encounters, we need to be appropriately ungrammatical" (p. 227). Consequently, the present understanding of CLT concepts can be traced back to Hymes.

\subsection{Role of Memorization in the Saudi Context}

Memorization may be effective in language learning, specifically at the beginner levels where learning new vocabulary or a new grammatical structure is crucial. However, the reliance on memorization comprehensively may result in limitations on acquiring the target language. In reference to Gass \& Schachter (1989), Linguistic Perspectives on Second Language Acquisition, the indication is that "the Monitor Model of Krashan made a distinction between "learning" and "acquisition," where the term "learning" refers to the conscious learning of explicit rules, and 'acquisition' is used to the unconscious internalization of knowledge. Conscious memorization of grammar rules is held- correctly-not to be the same thing as developing real language competence" (p.43). Noam Chomsky (1994), on the other hand, debates the effectiveness of Skinner's psychological school of behaviorism which emphasized the role of memorization and habit formation in learning by mimicking and drilling. His major contribution in the SLA literature of 'generative grammar' challenged such practices and still does. He claims that "the reduction of the learning task to the problem of memorization of a finite list means that the results, whatever they are, simply do not bear on the APS (poverty of stimulus) or on the question of the kind of complex learning mechanism that is required for language." Instead, Chomsky asserts that the importance of education should be placed on students' critical thinking skills and the development of attaining useful and relevant knowledge (Chomsky, 1994 as quoted in Otero, 1994, p. 302). It would be appropriate to state that this heavy reliance on memorization appears to decrease when the level of language proficiency is advanced.

From my experience in teaching in Saudi Arabia, there have been many occasions where English language students memorize whole paragraphs for writing assessment tests. In Saudi Arabia, for instance, this practice is very common and widespread at most educational stages starting from the elementary level to university level students. Additionally, it is very common to see two writing paragraphs that are almost identical, although the scripts are from two different students at the Eli preparatory year at the beginner language level. The obvious and almost complete resemblance between the two writing scripts is not necessarily the result of plagiarism, or of students copying each other's scripts in exams; but, rather, the resemblance is a direct result of memorizing a text sample used in class during pre-exam revision.

The learning strategy of memorization may appear sensible to learners; however, with time and frequent use, it may become a habit. Consequently, the learning strategy of memorization has been used and overvalued in the learning of other subjects including the English language, which is primarily true when there is no sufficient background experience in learning strategies.

In the Saudi education system, learners are not taught how to implement different learning 
strategies, which is highly disregarded. Unfortunately, some of our students' past experiences in English language courses are due to the lack of effective learning strategies which led them to build a negative attitude towards learning the English language. For instance, students achieved low scores in reading comprehension due to their lack of simple reading strategies, such as skimming and scanning for main ideas or vocabulary meaning. Thus, these learning strategies can be used not only directly for learning the language, but more importantly, indirectly for using the target language.

In a similar study that supports this claim, Al Asmari (2013) examined the effects of writing strategies on students' writing anxiety and writing achievement in 198 English-major students (68 males and 130 females) in a Saudi university. He found that Saudi EFL students seem to have similar challenges when writing, such as writing nervousness. Such challenges seem to be rooted at early stages of EFL education from their early school education. Moreover, some of these problems are rooted to the lack of background knowledge about skill based specific learning strategies in general, and writing strategies in particular. The findings of this study have supported the earlier claims about the influence on the learners' autonomy, learning experience, and more importantly, the lack of strategy instruction in Saudi educational institutions.

Along the same lines, Shukri (2014) confirms that the role of memorization of "basic texts" in Saudi Arabia continues to be central to the educational system today, which is traced back to the days of the 'Kuttab schools' (Rugh, 2002), where Islamic teachings from the Quran are taught by memorization. Furthermore, Shukri elaborates on the three apparent Saudi education characteristics which are government regulated curriculum, the intensive study of religion, and the common habit of memorization. These tactics force strict control on the learning processes (Smith, 2001), and as a result, learner autonomy therefore weakened, if not more possibly eradicated.

\subsection{English Language Learning in Saudi Arabia}

The role of memorization in the EFL classrooms plays an important role, as was seen in the previous section. The following section will focus on the background of English language learning specifically in Saudi Arabia.

The beginning of ties between the Saudi education system and the English language was around 1958, when the "teaching of English and French began in the newly established intermediate level education system" as cited by Mahboob \& Elyas (p.129). Similarly, Al-Abdulkader (1978) stated that English and French languages were presented to the secondary education system as a foreign language in the Saudi Era.

Learning core subjects such as math or chemistry is, as a matter of fact, different from learning a language. Unlike learning the subjects of math or chemistry, learning a new language requires broad exposure to the new language, as well as the encouragement and concentration from the learner to acquire the language. However, in Saudi Arabia, the instruction of the English language subject is similar to the instruction of other subjects. For instance, the traditional methods of teaching are usually implemented, and unfortunately the 
concept of accuracy over frequency succeeds. Teachers often cannot bear learner errors and, whether directly or indirectly, memorization as a learning strategy is fortified and accepted as the custom over other learning strategies. Accordingly, most Saudi learners have acquired a learning experience that relies greatly on memorization.

Since the beginning of the 1970s, language learners were acknowledged as responsible for their own learning as opposed to the previous traditional teacher-centered practices, where the learners were not perceived as active components in the learning circle. Rubin (1975), has investigated what learners did to become a 'good language learner' and has identified some of their learning strategies. Accordingly, when mentioning 'learning strategies' we refer to "the techniques or devices which a learner may use to acquire knowledge". (Freeman \& Anderson, p. 183). Therefore, as can be seen, such strategies need to be learner driven and goal oriented. Accordingly, strategies can "make learning easier, faster, more enjoyable, more self-directed, more effective, and more transferable to new situations" (Oxford, 1990, p. 8).

It is much more prevalent for English language learners in Saudi Arabia to implement the learning strategy of memorization based on repetition as opposed to other more developed learning strategies such as cognitive strategies. This heavy dependence on memorization is due to three particular reasons: the past learning experiences, the influence of the cultural background, and the lack of strategy instruction.

\section{Implementation of CLT in EFL Classes}

According to Hogan, Harkness, \& Lubinski, the importance of language is a principal tool in the manifestation, communication, and revision of culture, (2000). Moreover, language is not simply a means of reporting experience, but language is more significantly a way of defining experience (Sapir - Whorf Hypothesis 1986). As humans, we use language as a system of communication to store, retrieve, organize and express knowledge and experience (Ehrman, Leaver, \& Oxford, 2003).

In fact, the benefits and advantages of practicing CLT in the EFL classroom will be the increase of learner's oral communication skills and their motivation, due to the direct exposure to language and the use of authentic / cultural relative language. As such, learners overcome the fear of communicating in EFL and learn to communicate more effectively due to the heightened confidence and feel of security in the classroom. More specifically, the use of authentic material alongside class text provides ample opportunities for learner skills development as presented in CLT. In addition, this increases the teacher student relationship as an interactive relationship, where the instructor is merely the facilitator. Also, CLT promotes learner autonomy, the social nature of learning, a focus on meaning, development of thinking skills and diversity. Consequently, learners learn more from hearing the language used by their classmates, and as such they become more productive linguistically than if instructor was the center of the class.

Although no grammar rules are stressed in CLT, instructors may take more time and effort to select topics that are of an appropriate level or interest to present as grammar activities in the classroom. Therefore, the instructor ought to have good time management skills and the ability 
to better monitor students for their understanding, accuracy and interest. In the CLT classroom, instructors should modify their acumen about the role of the grammar within the language class. Priority may not be given to the activities that are grammar based; nevertheless, instructors should view the structure as their essential objectives. Along the same lines, instructors ought to remember that the purpose for teaching grammar is to help L2 learners be better communicators. This does not in any way intends to undermine grammar teaching. Instead, using grammar consciousness by offering tasks which helps the use and development of learner grammar skill knowledge, helps them become more proficient and confident in the English language at their corresponding level.

Applebee (1974) concurs that "teachers [are] encouraged to develop learning materials on the basis of the particular needs manifested by the class" (p. 150). This is in specific reference to an EFL learner-centered classroom. Similarly, Richards \& Rogers (2001) add that "individual learners possess unique interests, styles, needs and goals" (p. 158) which instructors must tap in when addressing the needs of the whole EFL learner.

Consequently, the learner textbooks used in an EFL class should emphasize on the quality of the classroom interaction in addition to language use. Although most school syllabuses have moved from using the traditional teaching method in a variety of EFL frameworks, most of the teachers remain attached on using traditional practices in the classes (Karim, 2004). Sato and Kleinsasser (1999) stated that many teachers were hesitant to apply communicative activities, and preferred a more traditional teaching approach than a communicative teaching method (Gamal \& Debra, 2001; Gorsuch, 2000). Moreover, Penner (1995) indicated that it was challenging for teachers to modify the traditional approach of language to the modern teaching approach. Incecay \& Incecay found that when teachers apply the traditional teaching method by putting more emphasis on grammar and students focus more on sentence structure, this leads to inhibiting learners from progressing their communicative proficiency (2009). On the other hand, Littlewood (1981) suggests that an overemphasis on grammar will lead to preventing learners from advancing their communicative competence.

According to Inecay \& Inecay (2009), a teachers' explanation of grammar exercise can be a waste of time, as it may give little chance for students to communicate with language. Interestingly, Incecay and Incecay (2009) observe that $90 \%$ of EFL teachers explain grammar rules in their mother tongue. This implies that students in EFL classrooms continue to be under a lot of pressure of learning the grammar, which is compulsory during their early year education. Littlewood (1981) maintains that many characteristics of language learning can take place only through 'natural processes', which function when a person is involved in using the language for communication and the main goal for the learner is to communicate with others. Doherty and Singh (2005) conclude that if students want to learn a new language effectively, they should take part actively in the communication with language rather than sentence structure and only passively accept what the teacher says. As a result, it can be seen that over-emphasis on grammar in the teaching and learning could be another difficulty when implementing CLT in the EFL classroom practice.

From my experience of teaching, the materials promoted communicative language use and 
were text based with practice exercises, reading passages, as well as fill in the blanks. Additionally, the materials include game boards, role play, pair and group work tasks, cards and realia such as magazine and newspaper clip outs, menus and maps with in the text. Moreover, instructors are supported with a bank of materials to use with such extra learner practice.

\section{Applying CLT in Saudi Arabia and the Middle East}

This previous section emphasized on the application of CLT in EFL classes, and the following section will focus on CLT application with references to studies from Saudi Arabia and the Middle East.

Hiep (2007) stated that "in order to use the language effectively, learners need to develop communicative competence" and be able to use the language they are learning in genuine situations (p. 193). The significance of this approach is associated with the need to eliminate the traditional way of teaching the language in Saudi Arabia, as well as the Middle East, and move on to a method that encourages learners to use the language in genuine situations. Here the paper will present and discuss the CLT application in English language learning classrooms at three universities in Saudi Arabia and in the Middle East.

A study conducted by Alasmari (2015) at Taif University titled Communicative Language Teaching in EFL University Context: Challenges for Teachers, states that with CLT the teacher's role should be a "model for correct speech" which should help students "produce plenty of error free sentences" (Richards 2006 p. 5). As such, the teacher's role is that of a facilitator, a guide and a co-learner, providing learners with an autonomous environment to help them take control of their learning in the classroom. However, the Taif University study shows student difficulties in the EFL classroom, and their resistance to participate in communicative activities. The study displays lack of student motivation and their need for using English outside of the classroom as some of the challenges.

The central role of CLT, as referred to by Al Asmari (2015), is communicative competence comprising of "what to say and how to say it appropriately based on the situation, the participants, and their roles and intentions" (Ozsevic 2010, p. 27). Yet, this study indicated that student resistance to participate in communicative activities is an indicator to their lack of motivation. In reference to motivation in Finocchiaro and Brumfit's features of CLT, the aim would be for teachers to help learners in any way that motivates them to work with the language. Moreover, the CLT features state that intrinsic motivation will spring from an interest in what is being communicated by the language. Ultimately, the display of low student motivation may direct the need to diligently apply the motivational factors listed in Finocchiaro and Brumfit's features of CLT.

Another challenge of CLT in EFL classrooms is the use of the traditional approach, where the teacher is the authority in the classroom and 'students do as the teacher says, so that the teacher's knowledge can be transferred to them' (Anton, 1999, p. 304). The CLT approach shifts the focus from the traditional teacher-centered classroom to a learner-centered classroom setting. Therefore, the new role of teachers in the classroom changes to being a 
facilitator and a monitor in the communicative process. On the other hand, learners will have the opportunity to negotiate and express their ideas and thoughts. Additionally, students will be responsible for their own learning under their teachers' supervision.

According to the study by Al-Khwaiter (2001), titled Communicative Language Teaching and Curriculum Innovation in the Teaching of English as a Foreign Language in Qatar: A Study of the Classroom and its Socio-Cultural Context, English is particularly important since it delivers interaction to Western science and technology, in addition to its role in the development of modernization. Al-Khwaiter proclaims that the attempt to introduce CLT methods into the English Language Teaching (ELT) curriculum in Qatar over the last thirty years was not successful, although the method was officially accepted by the Qatar Ministry of Education. Despite a rigorous in-service teacher training on the use of CLT methods, several evaluation reports in his study show that the pursuit to introduce CLT methods was met with refusal from the teachers.

The study focused on the beliefs and practices of teachers and students towards English language teaching and learning, and the findings suggest that their classroom culture was incompatible with the officially promoted CLT methodology. Moreover, the data in Al-Khwaiter's study shows that classroom conducts of the male expatriate Arab teachers reflect an authoritarian teaching style, which branches out from the hierarchical nature of Arab society. On a similar note found in Al-Khwaiter's paper, a study by Morad (1994, unpublished paper presented to ALECSO) suggests that expatriate male Arab teachers show resistance to CLT because it is "too demanding on the part of the teachers since they had to abandon their traditional method, change their role, change their lesson preparation, learn how to use new teaching aids and learn how to write communicative tests" (p. 43). Most significantly, Al-Khwaiter recommends that English language teachers' problems, training needs, motivation and relationship with students must first be deeply addressed, in the interest of improving the existing teacher training programs and their classroom practices.

The last twenty years has witnessed a change where there is a focus on the strategies applied for learners to understand, learn or remember information as the prime concern (Alhaisoni, 2012). A study conducted by Alhaisoni at the University of Hail in Saudi Arabia, Language Learning Strategy Use of Saudi EFL Students in an Intensive English Learning Context, revealed that learners at the university used cognitive and metacognitive strategies while learning English. The metacognitive strategies include actions that allow learners to both control and coordinate their own learning. Interestingly, students applying metacognitive strategies have strong instrumental motivation for learning English, and where they apply it to advance their academic and professional lives. This is vital, as the role of motivation is a significant in Finocchiaro and Brumfit's features of CLT.

The activities and materials that can be applied with CLT are unlimited. They should be designed to involve the learners in realistic communication as they encourage them to speak and stimulate communicative language use (Harmer, 2007). The core emphasis of CLT activities is the content of what learners want to say instead of the form, which could be an advantage that motivates learners to participate. This is in accordance with Finocchiaro and 
Brumfit's features of CLT, they state that language is created by the individual through trial and error. And, more relevantly, fluency is accepted over accuracy.

An alternative study by Shu-hua Wu and Sulaiman Alrabah (2014), titled Tapping the Potential of Skill Integration as a Conduit for Communicative Language Teaching, focuses on skill integration techniques used by English teachers in Kuwait. The survey in the study aimed to explore the teachers' attitudes toward the skill integration technique by recording 25 hours of classroom based observations and conducting interviews with the same group of teachers. The findings of this study showed teachers that participated performed tasks that included simultaneous integration of speaking, listening, reading and writing in their prospective classrooms.

However, although the findings indicated skill integration technique was used by most of the English teachers, teachers were hesitant toward its application in their classrooms. The cause for their hesitation was because of the negative washback effect of the traditional English tests measuring students' accurate application of grammar rule, rather than their fluency and ability to use L2 as a tool for communication. This highlights the need for English teachers to also develop communicative tests that involve skill integration, and stresses the development of the four language skills as part of their daily classroom activities. Again, stressing the factor that fluency is acceptable as the primary goal, and accuracy is judged not in the abstract but in context as stated in Finocchiaro and Brumfit's features of CLT.

According to another study from Ajloun National University in Jordan titled Motivations towards Learning English: The Case of Jordanian Gifted Students by Al-Khasawneh and Al-Omari (2015), the process of learning any language is said to be affected by several factors such as attitude, aptitude and motivation. These factors reflect on the motivational factors listed in Finocchiaro and Brumfit's features of CLT where teachers help learners in any way that motivates them to work with the language through trial and error to advance their aptitude. Consequently, teachers should think carefully before choosing classroom activities. According to Richards and Rodgers (2001), activities need to be selected according to learners involved "in meaningful and authentic language use (rather than merely mechanical practice of language patterns)" (p. 161). Therefore, for learning to take place, the material must have significance to the learners, and should also be important from learners' perspective (Krashen, 1981, 1982, 1985; Littlewood, 1984).

In addition to the importance for activities to have meaning, a study at King Saud University in Abha titled Rethinking Communicative Language Teaching: Reflection and the EFL Classroom, addresses the significant role of reflection in the EFL classroom. This study by Tarvin and Al-Arishi (1991) asserts that activities should encourage reflection. Again, another factor listed in Finocchiaro and Brumfit's features of CLT states that language is formed repeatedly by the individual through trial and error, just as with activities that seek self-reflection. Morgan et al. (1986) similarly declares that reflective thinking is "the process of evaluating or testing [one's] own reasoning... and allows the formal-operational person to be his or her own critic, to evaluate a process, idea, or solution from the perspective of an 
outsider and to find errors or weak spots in it" (p.470).

CLT has come under attack for having eroded the explicit teaching of grammar that will lead learners to lose 'accuracy in the pursuit of fluency' (Harmer, 2007, p. 71). Though, others have argued that there is no greater/less value in CLT activities than in traditional exercises (Harmer, 2007). Nonetheless, no one can deny that the CLT approach has left a permanent mark on teaching and learning that supports a different variety of classroom procedures.

\section{Applicability of CLT}

Ying specifies that language should be learned using a target language and communication (2010, unpublished master dissertation). According to Liao (2000), everyday communicative activities that provide information gap make it possible for language learners to communicate the target language in CLT approaches. Some common forms of communicative activities include role play, interviews, games, language exchanges, surveys, pair work and learning by teaching. According to Ying, the main aim of using such activities is to enhance learners' communicative competence (2010, unpublished master dissertation). Moreover, Menking (2001, Master Thesis) asserts that mastering a second or foreign language is not the mere outcome of paying attention to a teacher who conveys to students what and how to do tasks; but rather, with the CLT approach, it is the direct result of students being active listeners, speakers, readers and writers.

A consistent perspective among numerous teachers of Saudi Arabia is that the teaching of the language fundamentally incorporates the teaching of the knowledge about the language, rather than demonstrating as to how to utilize the language in a meaningful manner. This perspective could be because of the impact of the Grammar Translation Method that still, to a specific degree, penetrates language classes within Saudi Arabia and other Arab countries. Even with the measure of the government towards improving education, many Saudi educators are not equipped for becoming accustomed to change. Consequently, exploring this issue in the Saudi context becomes the objective of this investigation.

\section{Language Learning Strategies and CLT}

Language learning strategies (LLS) can help learners become effective language learners by facilitating students with a high degree of responsibility to advance their development in expanding their L2 skills. Crookall asserts that learners must continue learning even when they are no longer in a formal classroom setting (1988, cited in Oxford, 1989). Such language learning strategies will assist learners on improving their language proficiency, and integrate new information into their current "mental schemata." Moreover, Oxford (1990) contains in the definition of LLS that can be used for making learning 'more enjoyable for the learner'.

The aim of teaching is to assist learners to communicate in the target language. Similarly, Al-Khwaiter (2001) asserts that CLT is established on the belief that language is used primarily for communication. Additionally, Widdowson (1979) sustains that communication also takes place "by using sentences to make statements of different kinds, to describe, to record, to classify and so on, or to ask questions, make requests, give orders" (p. 18). 
Along the same lines, Savignon (1983) offers an example of a CLT reflection presented by Montaigne that he had learned Latin in an anti-structural way. Despite Montaigne stating that he learned "Without methods, without a book, without grammar or rules, without a whip and without tears, (he) had learned a Latin as proper as that of...(his) schoolmaster" (p. 47). Again, this view is essential, as it epitomizes the learning experience from the learner perspective precisely as "learning by doing.' This is also referred to as 'the experience approach" (Hilgard and Bower 1966), where it is a direct practice instead of a delayed practice of communication, which stands as a fundamental element of CLT.

\section{Discussion and Conclusion}

Highlighting the development of English language learning in the Middle East and Saudi Arabia in addition to the integration of CLT as part of English language learning is crucial for facing the challenges of the L2 learner. The light shed on the close affiliation with the role of learning strategies played in language learning specifically is fundamental. Although there is a heavy reliance on memorization for students learning English as a learning strategy, the main factors influencing the habit of memorization as a learning strategy are intertwined in cultural practices attained from early schooling.

Hiep (2005) attests that for the application of CLT to be fruitful, EFL instructors need to add meaning of CLT that suits the learner needs and classroom settings. Hence, the instructors of EFL should choose and alter parts of CLT that fit their classroom needs and setting. Therefore, language teachers need to adjust features in the CLT that is most adequate to their prospective classroom situation.

In summary, the six studies that highlight elements such as teacher roles as facilitators, learners controlling their learning, using authentic language to encourage attitude, aptitude and motivation, as well as applying reflection in the classroom learning. These elements need to be considered to focus more on learner needs in the EFL classroom. As such, CLT would be the ideal approach, as reflected in the aforementioned six studies.

In the first study by Alasmari (2015) from Taif University, he confirms that the teacher's role as a facilitator, guide and co-learner helps learners take control of their learning in the classroom. More relevantly, this study indicated that student resistance to participate in communicative activities is an indicator to their lack of motivation. The second study by Al-Khwaiter (2001) from Qatar suggests that their classroom culture was incompatible with the promoted CLT methodology. As such, he recommends that English language teachers must have rigorous training, thus elevating teacher motivation and improving their relationship with their students, which aim to improve their classroom practices.

Alhaisoni (2012) in the third study from University of Hail's focus is on the strategies employed for learners to understand, learn or remember information as the primary concern. The findings showed that learners at the university applied cognitive and meta cognitive strategies that allow them to control and coordinate their own learning. Interestingly, students applying metacognitive strategies have strong instrumental motivation for learning English.

The fourth study by Wu and Alrabah (2014), from Kuwait College of Business Studies, 
emphasized on skill integration techniques, and their survey explored teachers' attitudes toward skill integration. The findings of this study revealed the urgency for English teachers to also develop communicative tests that involve skill integration, in addition to developing the activities that encompass the four language skills. The fifth study by Al-Khasawneh and Al-Omari (2015) from Ajloun National University in Jordan states that the development of learning language is affected by several elements such as attitude, aptitude and motivation. Consequently, learners' activities should be carefully chosen according to how they involve the learner in meaningful and authentic language use. More precisely, for learning to take place, the study suggests that the material must have significance and be personally meaningful to the learner.

Lastly, the study by Tarvin and Al-Arishi (1991) from King Saud University in Saudi Arabia addressed the significant role of reflection in the EFL classroom. This study suggests that activities should encourage reflection as a "process of evaluating or testing [one's] own reasoning" and to "find errors" constructively.

As can be seen from the above studies, the application of the central elements from the CLT approach can be most effective for the learner. Elements that include learners using authentic/meaningful communication while stressing fluency over accuracy through learner self-reflection, in addition to trial and error. Similarly significant is applying motivational and meaningful activities to interest learners and meet the different personalities and needs of the learner. These principle elements will activate the learner mind to learn and remember the learned material successfully.

\section{Future Recommendation}

This paper provides perceptions on the use and success of the CLT approach in the EFL classrooms, and discusses different previous studies conducted at Saudi and Middle Eastern universities. Based on the findings, it is interesting to recommend further research that should include semi structured interviews and close observations of instructors in order to gain a deeper understanding on the practice of CLT of any specific setting. The research may highlight challenges faced by both instructors and students. Also, the study can help raise an awareness for international teachers of how CLT is applicable in the Arab context. Still, it presents recommendations in the area of CLT where additional researching of the CLT model may be needed.

\section{Acknowledgement}

We would like to thank Mr. Hussam Rajab and Mr. Sayyed Rashid Shah for their support and guidance.

\section{References}

Al Asmari, A. (2013). Investigation of writing strategies, writing apprehension, and writing achievement among Saudi EFL-major students. International Education Studies, 6(11), 130-143.

Alhaisoni, E. (2012). Language learning strategy use of Saudi EFL students in an intensive 


\section{Macrothink}

English learning context. Asian Social Science, 8(13), 115.

Al-Khasawneh, F. M., \& Al-Omari, M. A. (2015). Motivations towards Learning English: The Case of Jordanian Gifted Students. International Journal of Education, 7(2), 306-321.

Al-Khwaiter, J. (2001). Communicative language teaching and curriculum innovation in the teaching of English as a foreign language in Qatar: A study of the classroom and its socio-cultural context.

Anton, M. (1999). The Discourse of a Learner-centered Classroom: Sociocultural Perspectives on Teacher-Learner Interaction in the Second-Language Classroom. The Modern Language Journal, 83(3), 303-318.

Applebee, A. N. (1974). Tradition and Reform in the Teaching of English: A History. Urbana, Illinois: National Council of Teachers of English.

Brown, Douglas H. (1994). Teaching by Principles: An Integrative Approach to Language Pedagogy. USA: Prentice Hall Regents.

Bovitch, S. Cullimore, Z. Jones, T. Massas, T.\& Perum. D. (2011). The Educational Theory of Noam Chomsky 2011. NewFoundations. Online. Retrieved from http://www.newfoundations.com/GALLERY/Chomsky.html

Canale, M., \& Swan, M. (1980). Theoretical basis of communicative approach to second language learning and testing. Applied Linguistics, 1, 1-47.

Cook, V. (2003). Changing the first language in the L2 user's mind: Introduction toL2 effects on the L1(draft). Online. Retrieved from http://homepage.ntlworld.com/vivian.c/Writings/Papers/EffectsIntro.htm

Doherty, C., \& Singh, P. (2005). How the West is done: Simulating Western pedagogy in a curriculum for Asian international students. Internationalizing higher education (pp. 53-73). Springer Netherlands.

Ehrman, Leaver, \& Oxford. (2003). The Psychology of the Language Learner. Lawrence Erlbaum Associates Publishers. Retrieved from http://cstn.files.wordpress.com/2009/11/the-psychology-of-the-language-learner-3haxap.pdf

Finocchiaro, M., \& C. Brumfit. (1983). The Functional_Notional Approach: From Theory to Practice. New York: Oxford University Press.

Freeman, D., \& Anderson, M. (2011). Techniques \& principles in language teaching. Oxford: Oxford University Press.

Gass, S. M., \& Schachter, J. (1989). Linguistic perspectives on second language acquisition. England: Cambridge University Press.

Harmer, J. (2007). How to teach English. Person Education Limited: Longman.

Hilgard, E. R., \& G. H. Bower. (1966). Theories of Learning. New York: Appleton-Century-Crofts. 
Gamal, G., \& Debra, M. (2001). The Communicative Approach in Egypt: Exploring the Secrets of Pyramids. TEFL Journal, 1(2) 72-81.

Gorsuch, G. (2000). EFL Educational Policies and Educational Cultures: Influences on Teachers' Approval of Communicative Activities. TESOL Quarterly, 34, 675-710.

Hiep, P. H. (2005). "Imported" Communicative Language Teaching Implications for Local Teachers. Journal of English Teaching Forum, 43(4), 2-9.

Hiep, H, P. ( 2007). Communicative language teaching: unity within diversity. ELT Journal, 61(3), 193-201.

Howatt, A. P. R. (1984). A History of English Language Teaching. Oxford: Oxford University Press.

Hymes, D. H. (1972). On communicative competence. In C. J. Brumfit, \& Johnson (Eds.), The communicative approach to language teaching $\left(2^{\text {nd }}\right.$ ed.). Oxford University Press. pp. 5-27.

Hymes, D. (1972). On communicative competence in J. B. Pride and J. Holmes (Eds). Sociolinguistics (Part 1). Harmondsworth: Penguin. pp. 269-293.

Incecay, G., \& Incecay V. (2009). Turkish university students' perceptions of communicative and non-communicative activities in EFL classroom. Science Direct, 618-622.

Jiang, H. (2008). Effect of L2 phonetic learning on L1 vowels. Retrieved from http://summit.sfu.ca/item/9028

Kanik, M. (2012). The Effect of Content Instruction in L2 on L1 Pragmatics. Research in Language, 9(2), 93-110.

Karim, K. (2004). Teachers' perceptions, attitudes and expectations about Communicative Language Teaching (CLT) in post-secondary education in Bangladesh. (Doctoral dissertation, University of Victoria).

Krashen, S. (1981). Second Language Acquisition and second language learning. Oxford: Pergamon.

Krashen, S. (1982). Principles and practices in second language acquisition. London: Pergamon.

Krashen, S. (1985). The input hypothesis: Issues and implications. New York: Longman.

Larsen-Freeman, D. (Ed.). (2000). Techniques and principles in language teaching ( $\left.2^{\text {nd }} \mathrm{ed}.\right)$. Oxford: Oxford University Press.

Liao, X. Q. (2000). Communicative language teaching innovation is China: Difficulties and solutions. Accessed from ERIC E*-Journal. No. ED 443 294. (Access date: June 5, 2003).

Littlewood, W. (1981). Communicative Language Teaching. Cambridge: Cambridge University Press. 


\section{Macrothink}

Littlewood, W. (1984). Foreign and second language learning: Language acquisition research and its implications for the classroom. Cambridge: Cambridge University Press.

Mahboob. A., \& Elyas. T. (2014). English in the Kingdom of Saudi Arabia. World Englishes, $33(1), 128-142$.

Menking, S. (2001). The communicative approach to teaching English in post-secondary institutions in Shimane, Japan. Master Thesis, University of Southern Queensland, Australia ERIC database, (ED461994).

Morad, F. (1994). The situation of English language teaching in the state of Qatar from 1975 to 1990. Unpublished paper presented to ALECSO.

Morgan,C. T., King, R. A., Weisz, J. R., \& Schopler, J. (1986). Introduction to psychology $\left(7^{\text {th }}\right.$ ed.). New York: McGraw-Hill.

Otero, C. P. (Ed.). (1994). Noam Chomsky: critical assessments (Vol. 1). Taylor \& Francis.

Oxford, R. L. (1990). Language Learning Strategies. What Every Teacher should know? Boston: Newbury House Publishers.

Oxford, R. L., \& Nyikos, M. (1989). Variables affecting choice of language learning strategies by university students. Modern Language Journal, 73(2), 291-300.

Ozsevik, Z. (2010). The use of communicative language teaching (CLT): Turkish EFL teachers' perceived difficulties in implementing CLT in Turkey. (Doctoral dissertation, University of Illinois at Urbana-Champaign).

Pavlenko, A. (2000). L2 influence on L1 in late bilingualism. Issues in Applied Linguistics, $11(2)$.

R. Hogan, A. R. Harkness, \& D. Lubinski. (2000). Personality and Individual Differences. In Kurt Pawlik \& Mark R. Rosenzweig (eds.), International Handbook of Psychology (pp. 283-304). Sage Publications Ltd.

Pei-long, L. (2011). The study on the effectiveness of communicative language teaching strategies used in college English classes. Sino-US English Teaching, 8(7), 457-461.

Penner, J. (1995). Change and conflict: Introduction of the communicative approach in China. TESOL Canada Journal, 12(2), 1-17.

Richards, J. C. (2006). Communicative Language Teaching Today. Cambridge: Cambridge University Press.

Richards, J. C., \& Rogers, T. (2001). Approaches and Methods in Language Teaching. Cambridge, Cambridge University Press.

Rubin, J. (1975). What the "good language learner" can teach us. TESOL Quarterly, 9, 41-51.

Rugh, A. W. (2002). Education in Saudi Arabia: Choices and constraints. Middle East Policy, IX, 2, 40-55. 


\section{Macrothink}

Sapir, E. (1956). Culture, Language and Personality: Selected Essays, University of California Press. Digitized 2008.

Sato, K., \& Kleinsasser, R. (1999). Communicative Language Teaching (CLT): Practical Understandings. The Modern Language Journal, 83(4), 494-517.

Savignon, S. (1983). Communicative Competence: Theory and Classroom Practice. Reading, Mass.: Addison-Wesley.

Shukri, Nadia A. (2014). Second Language Writing and Culture: Issues and Challenges from the Saudi Learners' Perspective. Arab World English Journal, 3(5), 190-207.

Tarvin, W. L., \& Al-Arishi, A. Y. (1991). Rethinking Communicative Language-Teaching: Reflection and the EFL Classroom. TESOL Quarterly, 25(1), 9-27.

Tsai, T. H. (2007). Taiwanese educators' perspective on the implementation of the new English education policy. Unpublished doctoral dissertation. Alliant International University.

Widdowson, H. (1979). The teaching of English as communication. In C.Brumfit and K. Johnson (Eds.), The Communicative Approach to Language Teaching. Oxford: Oxford University Press.

Wu, Shu-hua, \& Alrabah, Sulaiman. (2014). Tapping the Potential of Skill Integration as a Conduit for Communicative Language Teaching. English Language Teaching, 11(7), 119-129.

Ying, L. (2010). Communicative activities in ELT classrooms in China. Unpublished master dissertation, University of Wisconsin-Platteville.

\section{Copyright Disclaimer}

Copyright for this article is retained by the author(s), with first publication rights granted to the journal.

This is an open-access article distributed under the terms and conditions of the Creative Commons Attribution license (http://creativecommons.org/licenses/by/3.0/). 